\title{
Research Priorities for mHealth and Innovative Strategies in Sexual and Reproductive Health and Rights in the WHO Africa Region
}

\author{
Leopold Ouedraogo ${ }^{*}$, Triphonie Nkurunziza ${ }^{1}$, Assumpta Muriithi ${ }^{1}$, Chilanga Asmani ${ }^{1}$, \\ Hayfa Elamin1, Souleymane Zan1, Bigirimana Françoise1, Mihretu Belete1, Gbenou Dina1, \\ Dadji Kwami', Mekdes Daba', Theopista Kabuteni John', Hien Clotaire1, Kim Caron Rahn', \\ Ali Moazzam², Tolu Lemi², Blami Dao ${ }^{3}$, Issiaka Sombie ${ }^{4}$, Okech Mollent ${ }^{5}$
}

\author{
${ }^{1}$ Reproductive, Maternal Health and Ageing, WHO Regional Office for Africa, Brazzaville, Congo \\ ${ }^{2}$ Department of Reproductive Health and Research, World Health Organization, Geneva, Switzerland \\ ${ }^{3}$ JHPIEGO, Ouagadougou, Burkina Faso \\ ${ }^{4}$ West Africa Health Organization, Ouagadougou, Burkina Faso \\ ${ }^{5}$ Peak Moments Global HR Solutions, Nairobi, Kenya \\ Email: ^ouedraogol@who.int
}

How to cite this paper: Ouedraogo, L., Nkurunziza, T., Mureithi, A., Asmani, C., Elamin, H., Zan, S., Françoise, B., Belete, M., Dina, G., Kwami, D., Daba, M., John, T.K., Clotaire, H., Rahn, K.C., Moazzam, A., Lemi, T., Dao, B., Sombie, I. and Mollent, O. (2021) Research Priorities for mHealth and Innovative Strategies in Sexual and Reproductive Health and Rights in the WHO Africa Region. Advances in Reproductive Sciences, 9, 33-40.

https://doi.org/10.4236/arsci.2021.91004

Received: October 24, 2020

Accepted: December 27, 2020

Published: December 30, 2020

Copyright $\odot 2021$ by author(s) and Scientific Research Publishing Inc. This work is licensed under the Creative Commons Attribution International License (CC BY 4.0).

http://creativecommons.org/licenses/by/4.0/ (c) (i) Open Access

\begin{abstract}
Background: The use of mobile phones continues to rise rapidly in the provision of health related services. Many countries have adopted the use of mobiles to provide sexual and reproductive health and rights and especially among the adolescents where specific messages are tailored for various audiences with specific messages. The purpose of this paper is to present the results of a research priority setting exercise on mHealth and innovative strategies. Methods: We adapted Child Health and Nutrition Research Initiative methodology to identify and set research priorities on mHealth and innovative strategies that respond to sexual and reproductive health and rights services. General potential research questions were gathered online from multiple stakeholders in the region and sent for consolidation consolidated to technical experts in World Health Organization headquarters. The second phase involved a meeting with experts to review and thematically analyze the questions list of 33 questions producing a list of 22 research questions. The questions were scored against a six point criteria and ranked accordingly. Ten top priority research questions were identified. Results: Lists of 33 priority research questions for mHealth and innovative strategies were proposed for discussions by 67 stakeholders. The questions were reviewed, scored and ranked in a technical meeting by experts. The highest ranking questions at $87 \%$ include evaluation of mHealth for data management and sexual and reproductive health and rights decision making, assessment of innovative local
\end{abstract}


financing techniques to support community based sexual reproductive health and rights and evaluation of the role of mobile technologies in referral and counter referral. Conclusions: Information and communication technology is developing drastically and has a great potential in improving health especially in sexual and reproductive health and rights service delivery. This potential must be demonstrated with more relevant and quality research on mHealth and innovative strategies priorities identified.

\section{Keywords}

mHealth, Mobile Phones, Sexual and Reproductive Health and Rights, Technology

\section{Introduction}

The importance of health technology in health care cannot be underestimated. Information and communication technologies have potential opportunities for the health care community with potent tools to improve health care [1]. Technology offers the ability to store, share and analyze health information increasing provider capabilities and patient access using Mobile Health (mHealth) as subcategory of electronic health (eHealth). Specifically, the information can be delivered through digital channels, such as the internet, mobile phone messaging, social media, apps, voice, video messaging, and telemedicine [2]. They are designed to provide interactive programs and interventions that can be targeted to particular groups or individuals and among diverse populations and offer potential for enhancing the delivery of services across disease statuses including sexual and reproductive health and rights (SRHR) information and support [3] [4].

With the rapid expansion of mobile phone ownership in low- and middle-income countries (LMICs) over the past decade, the field of mobile health (mHealth) has emerged as a novel and potentially cost-effective way to increase access to health information and improve health knowledge as well as health outcomes [5]. A wide range of sexual and reproductive health and rights services are provided via telemedicine, including hormonal contraception, medication abortions, and sexually transmitted infection (STI) care [6] [7]. These services could replace the need for in-person care in some cases, although most telemedicine services today still function as an adjunct to the existing health care system.

Despite its ability to reach wide audiences relatively cheaply and to convey tailored, appropriate health information to individuals, mHealth utilization by patients is still low and significant barriers exist to its implementation. Initiating a mHealth program entails significant investment in technology, and requires overcoming logistical challenges including privacy concerns, licensing and malpractice coverage [8].

Recent evidence suggests that mHealth programs can increase average health knowledge and that these programs are generally well-received by women and 
youth [9] [10]. However, very little is known regarding the reach and effectiveness of these programs in populations with key risk factors [11]. mHealth can thus potentially provide solutions for health challenges and for health systems that struggle with limited point-of-care services, low staff: patient ratios and lack of access for remote patients, as well as for sexual and reproductive health and rights (SRHR).

A World Bank report tracked more than 500 mHealth studies, and many donor agencies are lining up to support the "scaling up" of mHealth interventions [12]. Yet, after completion of these 500 pilot studies, we know almost nothing about the likely uptake, best strategies for engagement, efficacy, or effectiveness of these initiatives. Currently, mHealth interventions lack a foundation of basic evidence [13] let alone a foundation that would permit evidence-based scale up. The main objective of this paper is to present the findings of a research prioritization exercise conducted by WHO Africa Region on mHealth and innovative strategies in sexual and reproductive health services.

\section{Methods}

This paper reports part of a larger research prioritization exercise conducted by the WHO African region in 2019. The paper focuses on mHealth and innovative strategies on sexual and reproductive health and rights. We adopted the Child Health and Nutrition Research Initiative (CHNRI) methodology [14]. This method informs health policy and practice and aims at increasing the level of communication and discussion amongst experts at three stages. The prioritization exercise was implemented in three phases: 1) Generation and collection of research areas 2) review, consolidation and thematic analysis of questions 3) scoring and ranking of the priorities using a consensus based criteria.

Questions were administered online to experts from various organizations in the region to identify researchable areas basing their answerability, effectiveness, deliverability, equity and potential impact in the communities. The questions were received by a team from WHO HQs and analyzed building on the results from a prior research prioritization exercise conducted by EMRO and AFRO in 2016 [15]. Phase II and III of the exercise were conducted in a meeting held in Cape Town, South Africa from 29th October to 1st November, 2019 with 67 experts. A list of 33 potential research questions on mHealth and innovative strategies were proposed. The list served as the basis further review on this thematic area. The questions were revised and areas of duplications were merged. Phase two proposed 22 researchable questions after a rigorous process with 2 new additions. During the ranking process the experts adopted a modified version of CHNRI. They prioritized research questions that would maximize the impact of health investments in resource poor settings, those that had a great public benefit, cost effective and those questions that were feasible. The researchable questions were finally scored and ranked against magnitude, severity, effectiveness, feasibility, burden and equity. Table 1 below summarizes the ranking criteria used. 
Table 1. Scoring criteria for the research questions.

\begin{tabular}{|c|c|c|}
\hline Criteria & Definition & Scoring \\
\hline 1) Magnitude & $\begin{array}{l}\text { Magnitude of the problem; in terms of the proportion of the population, such as women, under } 5 \\
\text { children, elderly, are affected. }\end{array}$ & $1-2-3-4-5$ \\
\hline 2) Severity & $\begin{array}{l}\text { Of the condition; i.e. danger to the individual and the community. How serious is the condition. Does it } \\
\text { threaten life, cause major suffering, and decrease the ability to lead a normal life. }\end{array}$ & $1-2-3-4-5$ \\
\hline 3) Effectiveness & $\begin{array}{l}\text { Based on the best existing evidence and knowledge, would intervention be efficacious in reducing disease } \\
\text { burden? It is likely to be effective under programme conditions }\end{array}$ & $1-2-3-4-5$ \\
\hline 4) Feasibility & $\begin{array}{l}\text { Taking into account a) the infrastructure and resources required to deliver effective interventions (e.g. } \\
\text { human resources, health facilities, communication and transport infrastructure), and b) the need for } \\
\text { change in demand, beliefs and attitudes of users, would you say that the endpoints of the research would } \\
\text { be deliverable? affordability and sustainability }\end{array}$ & $1-2-3-4-5$ \\
\hline 5) Burden & $\begin{array}{l}\text { Diseases burden reduction; taking into account the best available information, would you say that } \\
\text { reaching of research endpoints would eventually, have a "capacity" to impact directly and indirectly } \\
\text { disease burden. E.g. up to } 5 \% \text { to } 10 \% \text { reduction in long run. }\end{array}$ & $1-2-3-4-5$ \\
\hline 6) Equity & $\begin{array}{l}\text { Equity enhancing; does the intervention affect mainly the underprivileged in the population? } \\
\text { Intervention has potential to improve equity in disease burden distribution in the longer term? }\end{array}$ & $1-2-3-4-5$ \\
\hline
\end{tabular}

1 is the lowest score and 5 the highest score. Each question could therefore attain a lowest score of 6 or highest score of 30.

\section{Results}

The aim of this exercise was to establish a list of priority research questions in mHealth and innovative strategies for SRHR services. In this paper, we report the results of the process. Table 2 highlights how the questions were scored according the criteria adopted. "Evaluation of mHealth for data management and SRHR decision making", "assessment of innovative local financing techniques to support community based SRHR" and "evaluation of the role of mobile technology in referral and counter referral" were scored at 26 points out of maximum 30 points. The next set of two questions on "feasibility and cost effectiveness of menstrual hygiene" and evaluating approaches for introduction of innovative SRHR interventions in low and middle income countries' were scored at 25 points. Other studies have reported the use of mHealth to improve results in maternal child health programs has improved communications by focusing on appointment reminders to increase access to and demand for antenatal and other maternal health clinic services, SMS messaging to improve health-seeking behaviors, and mobile phone applications for improving data collection (accuracy, reliability and completeness despite these there a few studies that have reported on the report on the correlation of mHealth with health outcomes.

\section{Discussion}

The research prioritization exercise identified top ten questions that the WHO Africa region could focus on in the next three years. While acknowledging that mHealth was critical for SRHR, the experts identified priorities for health research in mHealth and innovative strategies that were essential and could maximize the impact of investments in resource constrained environments, those 
Table 2. Scoring of the research questions.

\begin{tabular}{|c|c|c|c|c|c|c|c|}
\hline Title of the research questions & Magnitude & e Severity & Effectiveness & Feasibility & Burden & Equity & $\begin{array}{l}\text { Total } \\
\text { scores }\end{array}$ \\
\hline $\begin{array}{l}\text { 1) Evaluation of mHealth for data management and SRHR decision } \\
\text { making }\end{array}$ & 5 & 4 & 4 & 3 & 5 & 5 & 26 \\
\hline $\begin{array}{l}\text { 2) Assessment of innovative local financing techniques to support } \\
\text { community based SRHR }\end{array}$ & 5 & 5 & 5 & 2 & 4 & 5 & 26 \\
\hline $\begin{array}{l}\text { 3) Evaluation of the role of mobile technology in referral and } \\
\text { counter referral }\end{array}$ & 5 & 4 & 5 & 3 & 4 & 5 & 26 \\
\hline 4) Feasibility and cost effectiveness of menstrual hygiene & 4 & 4 & 4 & 4 & 4 & 5 & 25 \\
\hline $\begin{array}{l}\text { 5) Evaluating approaches for introduction of innovative SRHR } \\
\text { interventions in low and middle income countries }\end{array}$ & 4 & 4 & 3 & 5 & 4 & 5 & 25 \\
\hline $\begin{array}{l}\text { 6) Application of the on the job distant skill building using mobile } \\
\text { technology for SRHR }\end{array}$ & 5 & 4 & 3 & 3 & 4 & 5 & 24 \\
\hline $\begin{array}{l}\text { 7) Assessment of the policy environment for public private } \\
\text { partnership in SRHR service provision }\end{array}$ & 4 & 4 & 4 & 4 & 3 & 5 & 24 \\
\hline $\begin{array}{l}\text { 8) Evaluation of mobile based diagnostic algorithms in supporting } \\
\text { the management of SRHR complications at health facilities }\end{array}$ & 4 & 3 & 4 & 3 & 4 & 5 & 23 \\
\hline $\begin{array}{l}\text { 9) Assessment of innovative community engagement } \\
\text { strategies/techniques to improve SRHR service delivery }\end{array}$ & 5 & 4 & 3 & 2 & 4 & 5 & 23 \\
\hline 10) Evaluation of SRHR policy implementation & 4 & 4 & 4 & 3 & 3 & 5 & 23 \\
\hline
\end{tabular}

questions that could provide the highest public health benefits, cost effective and feasible in terms of implementation and mobilization of resources.

Information and communication technology is a promising area for health communities due to its potential for discreet, personal and adaptable communication and interventions that relatively reach a wider audience with tailor made messages to individual and groups [16] [17]. In most countries, both health and ICT polices recognize the potential of mHealth and other innovative strategies in delivery of health care especially on SRHR service delivery [18]. Information and communications technology should therefore be taken into account when planning for health.

Evidence available suggests that mHealth programs have the capacity to increase general health knowledge and that these programs are generally utilized and well received by the adolescents and the urban majority [2]. However, very little is known regarding the reach and effectiveness of these programs in populations with key risk factors. Also, mobile phone ownership and usage has greatly expanded among young people in many low middle income countries, adolescents from disadvantaged groups generally have reduced rates of phone ownership or may only have limited access to a shared household phone [19]. In addition, youth from these key populations may face other barriers pertinent to mHealth such as low technological literacy, poor network coverage, and language in competencies competency [20].

In this research priority setting exercise, it emerged that mHealth can be used 
to manage data for decision making in SRHR, assess innovative local financing mechanism to support community based SRHR interventions and feasibility and cost-effectiveness of menstrual hygiene products. Studies have demonstrated that mHealth programs have the potential to engage and increase SRHR knowledge of adolescent girls across socio-demographic strata, including those who may be at higher risk of poor SRHR outcomes [21]. mHealth interventions have demonstrated effectiveness in managing data for decision making, service utilization, treatment adherence, and behavior change amongst others [22]. mHealth interventions offer many advantages over in-person delivery of interventions; mHealth leverages existing technology, is flexible, cost effective, and can be uniquely tailored per user [23]. Given the impact of the global COVID-19 pandemic on in-person adolescent programs, services and interventions, it is imperative to highlight promising strategies to promote sexual and reproductive health and wellbeing.

\section{Conclusion}

Priority research areas in mHealth and innovative strategies in sexual and reproductive health and rights were identified. The research priority list can be utilized by key stakeholders including researchers, policy makers and funders. mHealth has great potential in sexual and reproductive health and rights service delivery as it can improve access to care, support clinical data collection, patient engagement and adherence to treatment plans and better outcomes. This potential can be further demonstrated by high quality research.

\section{Acknowledgements}

We thank all the experts who were involved in the research prioritization exercise for WHO Africa Region. They include: Zan Souleymane, Moufalilou Aboubakar, Bokossa Alexis Richard, Gaston D. Ahounou, Dina Gbenou, Hien Clotaire, Kiemtoré Sibraogo, Traoré IsidoreTiandiogo, Bassounda, Poïdigem, Dadjoari Moussa, Nguetabe Odile, Awad Adam Awad, Foumsou, Kini Brigitte Nsiku, Haimanot Ambelu Workineh, Tenaye Kebede, Girma Gemechu, Mekdes Daba, Deo Roseline, Samuel Oppong, Ivy Osei, Patrick K. Aboagye, Sy Telly, Férida Mara, Alpha Ahmadou Diallo, Tessougue Fatoumata, Idrissa Cissé, Sidy Diallo, Ben Moulaye Haidara, Moussa Kamissoko, Ojo Olumuyiwa, Ufere Joy, Ikpeze Okechukwu Christian, Chris Ega, Kabuteni Theopista John, Utumatwishima Jean Nepo, Ndaruhutse Victor, Ruzindana Kenneth, Mihretu Belete, Sithembile Dlamini-Nqeketo, K.S. Dithole, Rapinyana O., Ntombi Mtshali, Mercy Pindani, Azwihangwisi Helen Mavhandu-Mudzusi, Uta Lehmann, Boniface Ushie, David Norris, Blami Dao, Issiaka Sombie, Seni Kouanda, Richard Adanu, Goma Mboungou Mierette, Mavounia Ndoko Genil, Ngwenya, Mmamoitlamo and Mncwabe Pearl.

\section{Funding}

The WHO Regional office for Africa. 


\section{Conflicts of Interest}

The authors declare that they have no competing interests.

\section{References}

[1] World Bank (2016) The Little Data Book on Information and Communication Technology 2015. World Bank, Washington DC.

[2] Aranda-Jan, C.B., Mohutsiwa-Dibe, N. and Loukanova, S. (2014) Systematic Review on What Works, What Does Not Work and Why of Implementation of Mobile Health (mHealth) Projects in Africa. BMC Public Health, 14, Article No. 188. https://doi.org/10.1186/1471-2458-14-188

[3] Mehl, G. and Labrique, A. (2014) Prioritizing Integrated mHealth Strategies for Universal Health Coverage. Science, 345, 1284-1287. https://doi.org/10.1126/science.1258926

[4] De Tolly, K. and Constant, D. (2014) Integrating Mobile Phones into Medical Abortion Provision: Intervention Development, Use, and Lessons Learned from a Randomized Controlled Trial. JMIR mHealth and uHealth, 2, e5. https://doi.org/10.2196/mhealth.3165

[5] Kay, M., Santos, J. and Takane, M. (2011) mHealth: New Horizons for Health through Mobile Technologies. World Health Organization, 64, 66-71.

[6] United Nations Population Fund. Empowering People to Ensure a Sustainable Future for All.

http://www.unfpa.org/news/unfpa-launches-advocacy-platform-post-2015-develop ment-framework

[7] Tomlinson, M., Rotheram-Borus, M.J., Swartz, L. and Tsai, A.C. (2013) Scaling Up mHealth: Where Is the Evidence? PLOS Medicine, 10, e1001382.

https://doi.org/10.1371/journal.pmed.1001382

[8] Piette, J.D., Lun, K.C., Moura, L.A., Fraser, H.S., Mechael, P.N., et al. (2012) Impacts of e-Health on the Outcomes of Care in Low- and Middle-Income Countries: Where Do We Go from Here? Bulletin of the World Health Organization, 90, 365-372. https://doi.org/10.2471/BLT.11.099069

[9] Free, C., Phillips, G., Watson, L., Galli, L., Felix, L., et al. (2013) The Effectiveness of M-Health Technologies to Improve Health Care Service Delivery Processes: A Systematic Review and Meta-Analysis. PLOS Medicine, 10, e1001363.

https://doi.org/10.1371/journal.pmed.1001363

[10] Briscoe, C. and Aboud, F. (2012) Behaviour Change Communication Targeting Four Health Behaviours in Developing Countries: A Review of Change Techniques. Social Science \& Medicine, 75, 612-621. https://doi.org/10.1016/j.socscimed.2012.03.016

[11] Lemaire, J. (2011) Scaling up Mobile Health: Elements Necessary for the Successful Scale Up of mHealth in Developing Countries. Advanced Development for Africa, Geneva.

[12] Qiang, C.Z., Yamamichi, M., Hausman, V. and Altman, D. (2011) Mobile Applications for the Health Sector. World Bank, Washington DC.

[13] Collins, F. (2012) How to Fulfill the True Promise of "mHealth": Mobile Devices Have the Potential to Become Powerful Medical Tools. Scientific American, 307, 16. https://doi.org/10.1038/scientificamerican0712-16

[14] Rudan, I., Chopra, M., Kapiriri, L., Gibson, J., Lansang, M.A., et al. (2008) Setting 
Priorities in Global Child Health Research Investments: Universal Challenges and Conceptual Framework. Croatian Medical Journal, 49, 398-408. https://doi.org/10.3325/cmj.2008.3.307

[15] Ali, M., Farron, M., Quedraogo, L., Mahaini, R.K., Miller, K. and Kabra, R. (2018) Research Gaps and Emerging Priorities in Sexual and Reproductive Health in Africa and Eastern Mediterranean Regions. Reproductive Health Journal, 15, Article No. 39. https://doi.org/10.1186/s12978-018-0484-9

[16] Mendis, S. and Alwan, A. (2011) Prioritized Research Agenda for Prevention and Control of Noncommunicable Diseases. World Health Organization, Geneva.

[17] Souza, J.P., Widmer, M., Gülmezoglu, A.M., Lawrie, T.A., Adejuyigbe, E.A., Carroli, G., Crowther, C., Currie, S.M., Dowswell, T., Hofmeyr, J., et al. (2014) Maternal and Perinatal Health Research Priorities beyond 2015: An International Survey and Prioritization Exercise. Reproductive Health, 11, Article No. 6.

https://doi.org/10.1186/1742-4755-11-61

[18] Waldman, L. and Marion, S. (2015) Sexual and Reproductive Health and Rights and mHealth in Policy and Practice in South Africa. Reproductive Health Matters, 23, 93-102.

[19] Mitchell, K.J., Bull, S., Kiwanuka, J. and Ybarra, M.L. (2011) Cell Phone Usage among Adolescents in Uganda: Acceptability for Relaying Health Information. Health Education Research, 26, 770-781. https://doi.org/10.1093/her/cyr022

[20] Blumenstock, J.E. and Eagle, N. (2012) Divided We Call: Disparities in Access and Use of Mobile Phones in Rwanda. Information Technologies \& International Development, 8, 1-16.

[21] Rokicki, S. and Fink, G. (2017) Assessing the Reach and Effectiveness of mHealth: Evidence from a Reproductive Health Program for Adolescent Girls in Ghana. BMC Public Health, 17, Article No. 969. https://doi.org/10.1186/s12889-017-4939-7

[22] de Francisco, A.d.A.C., Ringheim, K., Liwander, A., Peregoudov, A., Faich, H.S., et al. (2009) Perceived Research Priorities in Sexual and Reproductive Health for Lowand Middle-Income Countries: Results from a Survey. Global Forum for Health Research, Geneva.

[23] Rokicki, S., Cohen, J., Salomon, J.A. and Fink, G. (2016) Impact of a Text-Messaging Program on Adolescent Reproductive Health: A Cluster-Randomized Trial in Ghana. American Journal of Public Health, 107, 298-305.

https://doi.org/10.2105/AJPH.2016.303562

\section{Abbreviations}

CHNRI: Child Health and Nutrition Research Initiative; SRHR: Sexual and Reproductive Health and Rights; WHO: World Health Organization; LMICs: Low and Middle Income Countries. 